\title{
Reseach Old Rubber Tires Utilization to Increase the Life of Support in the Longwall at Quang Ninh Vietnam
}

\author{
Phi Hung Nguyen ${ }^{1, *}$, Cao Khai Nguyen ${ }^{1}$, Duc Thang Pham ${ }^{2}$, and Van Kien $\mathrm{Ta}^{2}$ \\ ${ }^{1} \mathrm{Ha}$ Noi University of Mining and Geology \\ ${ }^{2}$ Quang Ninh University of Industry, Quang Ninh, Vietnam
}

\begin{abstract}
In longwall mining where use frame support and control roof by full caving; rocks could impact the support, damage some its details and reduce support's longevity. Using waste, elastic, and deformable capability materials (like old truck tires) not only reduce impulse which impact the support fatally and increase support's longevity, but also contribute to protect the environment.
\end{abstract}

\section{Introduction}

Use the frame support in control roof longwall by full-caving usually occurring the phenomenon of rock impacting into the stone shields during fire caving. The rock's impulse will reduce the life span of the frame support, especially the upper and lower stone shield $[1,2,3]$. How to increase the life span of the stone shield?

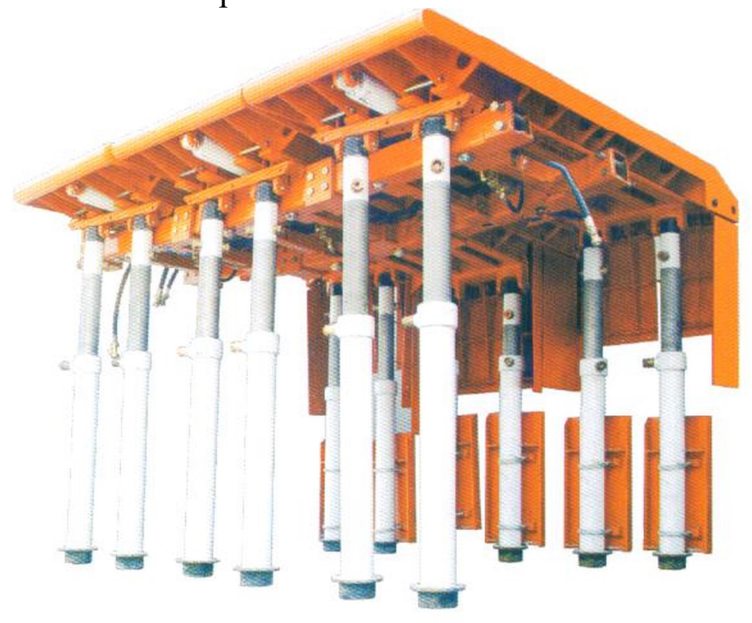

Fig. 1. Hydraulic frame support

\footnotetext{
*Corresponding author: hunguni@gmail.com
} 
During mining operations, there are some waste materials such as rubber tires, conveyor belts... being materials that can be utilized to reduce the stone impulse to impact on the resistance and increase the life of the shield [4].

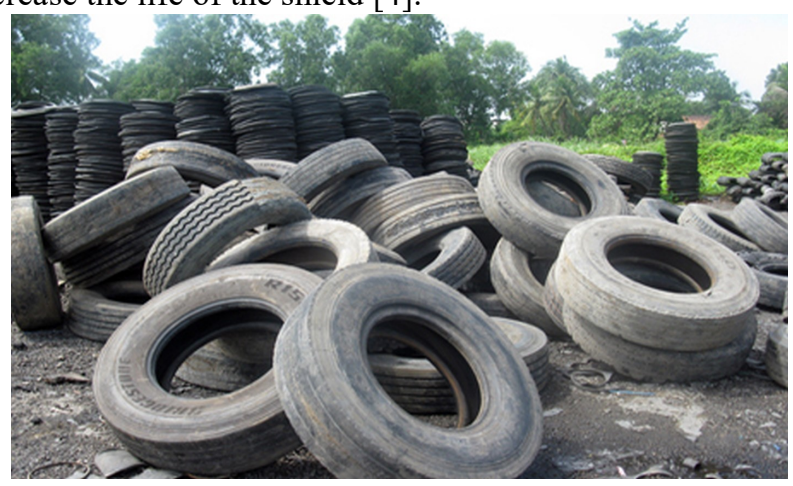

Fig. 2. Old truck tires

\section{Causes of frame support damage}

After caving, stone-impulse, one part directly destroys the deformable areas of the front and rear rock shields, and the rest is rapidly propagated through hard-to-deformation areas (where the rock shields contact with hydraulic support) to the hydraulic support, causing the support to be pushed horizontally. The impulse impacting on the shields by the fullcaving cycle will cause fatigue breakdown phenomenon $[5,6,7,8]$.

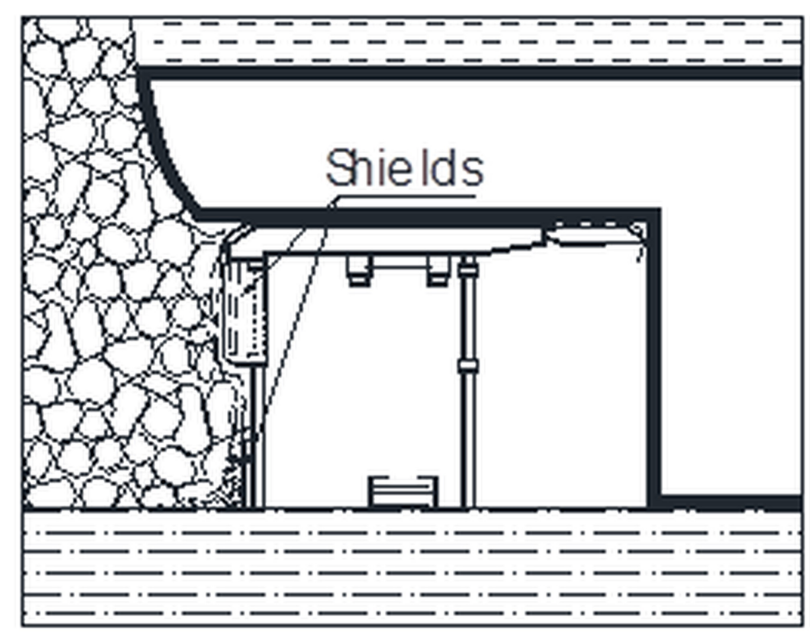

Fig. 3. Process of rock impacting on frame support after caving (Initial status) 


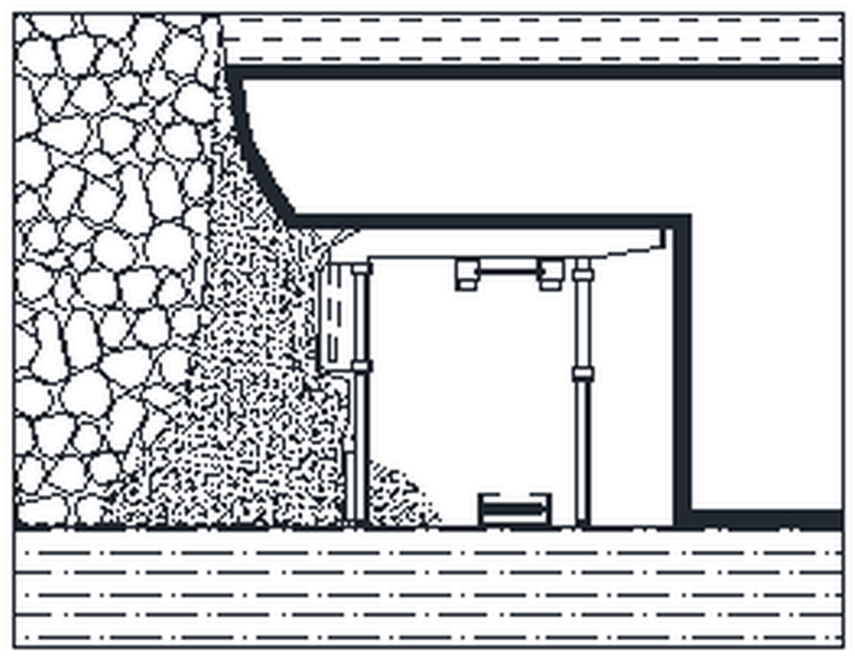

Fig. 4. Process of rock impacting on frame support after caving (Reclaim and preparation for caving)

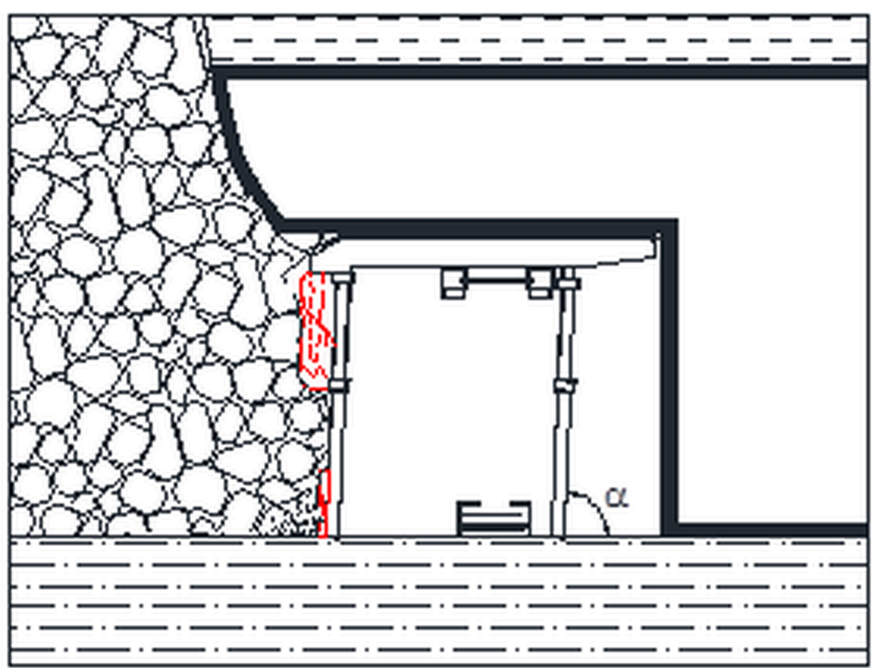

Fig. 5. Process of rock impacting on frame support after caving (Status after caving)
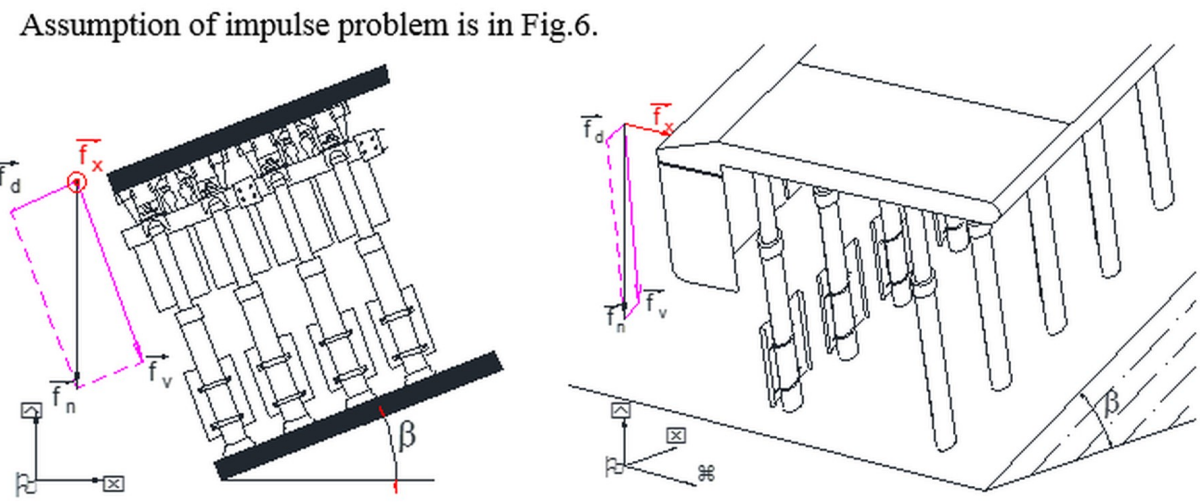

Fig. 6. Analysis of the impact force of the rock on frame support during caving 
When rock contacting ground, rock's force as in (1):

$$
\vec{F}_{n}=\vec{F}_{d}+\vec{F}_{v}
$$

Where: $\vec{F}_{n}$ - Rock's force during ground contact; $\vec{F}_{d}$ - Formational slope same direction force; $\vec{F}_{v}$ - Formational slope perpendicular force.

Rock is pressed by $\vec{F}_{n}$ then broken and causing $\vec{F}_{x}$ force impacting on frame support. This force's source is perpendicular to $\vec{F}_{d}$ and $\vec{F}_{v}$.

According to the conservation of energy law, the highest force of caving rock on the shield of the frame support is equal to the force acting directly on the base of the floor, as in (2).

$$
F_{x \max }=F_{n}
$$

$F_{n}$ can be calculated by the law of momentum conservation, as in (3):

$$
\vec{F}_{n}=\frac{M \cdot \overrightarrow{\Delta v}}{\Delta t}=M \cdot \vec{a}
$$

Where: M - Volume of caving rock; $\overrightarrow{\Delta v}$ - Velocity reduction; $\Delta t$ - Impact time; $\vec{a}$ Acceleration of caving rock from grounding to stopping.

Algebra value of $\vec{a}$ can be calculated as in (4):

$$
v_{1}^{2}-v_{0}^{2}=2 a \cdot \Delta s \Rightarrow a=\frac{v_{0}^{2}}{\Delta s}
$$

Where: $\mathrm{v}_{2}-$ Velocity when rock stops $\left(\mathrm{v}_{2}=0 \mathrm{~m} / \mathrm{s}\right) ; \mathrm{v}_{1}-$ Velocity when rock starts to contact support foundation; $\Delta \mathrm{s}$ - The distance of the rocky road (equal to the average settlement of the foundation). (5):

From (3), (4)and apply the law of conservation of mechanical energy, rock's force as in

$$
F_{n}=\frac{M \cdot v_{0}^{2}}{2 \Delta s}=\frac{W_{d}}{\Delta s}=\frac{W_{t}}{\Delta s}=\frac{M \cdot g \cdot h}{\Delta s}=\frac{\gamma \cdot r \cdot h_{z} \cdot L \cdot g \cdot h}{\Delta s}
$$

Where: $\mathrm{W}_{\mathrm{d}}$ - Motional energy of rock when contacting ground; $\mathrm{W}_{\mathrm{t}}$ - Potential energy of rock when not caving; $\gamma$ - Volume weight of rock; $r$ - Width of pull; $h_{z}$ - Height of collapse and breakdown area; L - Breakage length; $g$ - acceleration of gravity; $h$ - Breakage height.

Height of collapse and breakdown area can be calculated by the Morth formula (1954), as in (6):

$$
h_{z}=\frac{v \cdot L}{2 \cdot(1-v}
$$

Where: $v$ - Poisson ratio.

So the highest pressure on each shield, as in (7):

$$
P_{\max }=F_{n} \cdot S=\frac{\gamma \cdot r \cdot h_{z} \cdot L \cdot g \cdot h \cdot S}{\Delta s}
$$

Where: S - Shield's area.

\section{Measures to increase longevity for frame support}

The treatment method is to add an impulse absorption zone (IAZ) with effect $[9,10]$ :

- Reduce initial impact force $F_{x}$; 
- Scatter the impulse before impacting the shield.

In essence, the IAZ is the peripheral buffer for the components to be protected.

According to the theory of momentum conservation, the force acting on the shield without absorption as in (8):

$$
\vec{F}=\frac{m \cdot \overrightarrow{\Delta v}}{\Delta t}
$$

Where: $\vec{F}$ - Force acting on frame support; $\overrightarrow{\Delta v}$ - Reduction of velocity of load bearing object; $\Delta t$ - Impact time; $\mathrm{m}$ - Volume of load bearing object.

When adding the IAZ, :

- Increase the time $(\Delta \mathrm{t})$ of the initial thrust impacting the shield causing impulse reduction;

- With the structure of the absorption area, the force is divided into different forces of different senses, so the total impulse (perpendicular to the shield) decreases.

According to the law of energy conservation, rock energy causes more deformation of the IAZ, smaller the energy causing deformation, the frame support movement is.

So choose materials that are capable of large deformation as the absorption. However, this material must be reused after each caving. Only the elastic material can satisfy these two conditions.
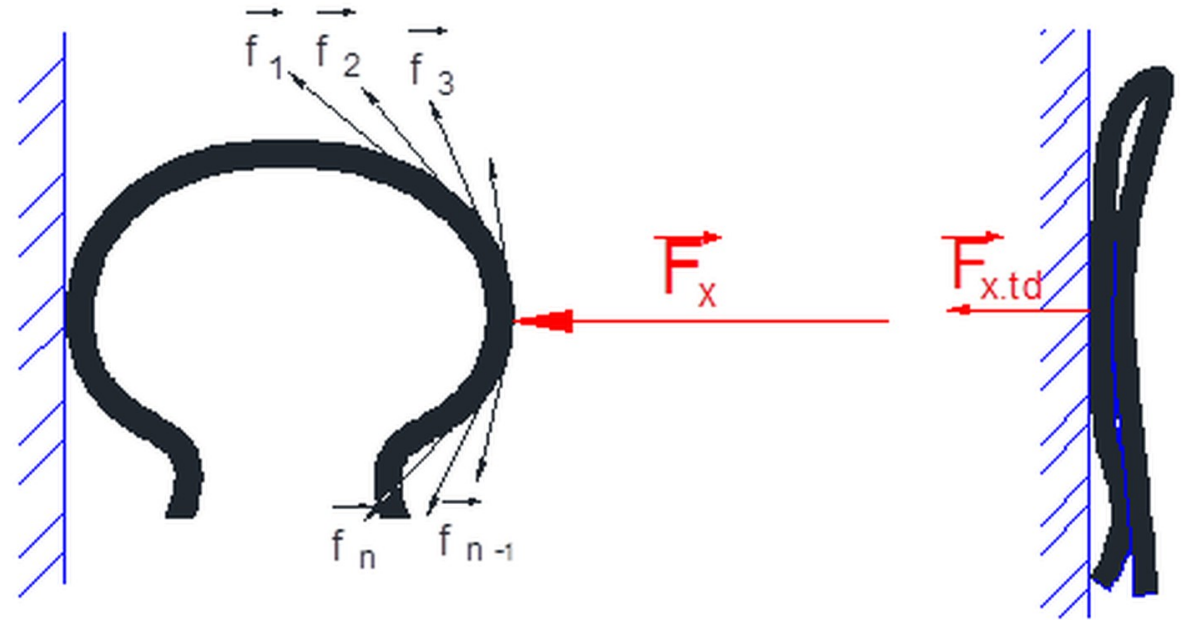

Fig. 7. Description of operating principle of the IAZ

During mine operation as well as in daily life, there are many exhausted elastic materials such as automobile tires, motorcycle tires; conveyors ... These materials are often discarded because they no longer meet the standards of friction, adhesion, but the deformability and elasticity are still very high, so it is entirely possible to use for the IAZ of frame support.

The way to mount this material on the shield of the frame support must ensure:

- Not reduce the bearing capacity of the shield;

- Keep material from falling under rock impact;

- The material has the highest deformability;

- Easy to install, replace.

To meet the above criteria, theyare arranged as in Fig.8 and Fig.9. 


\section{Old truck tire}
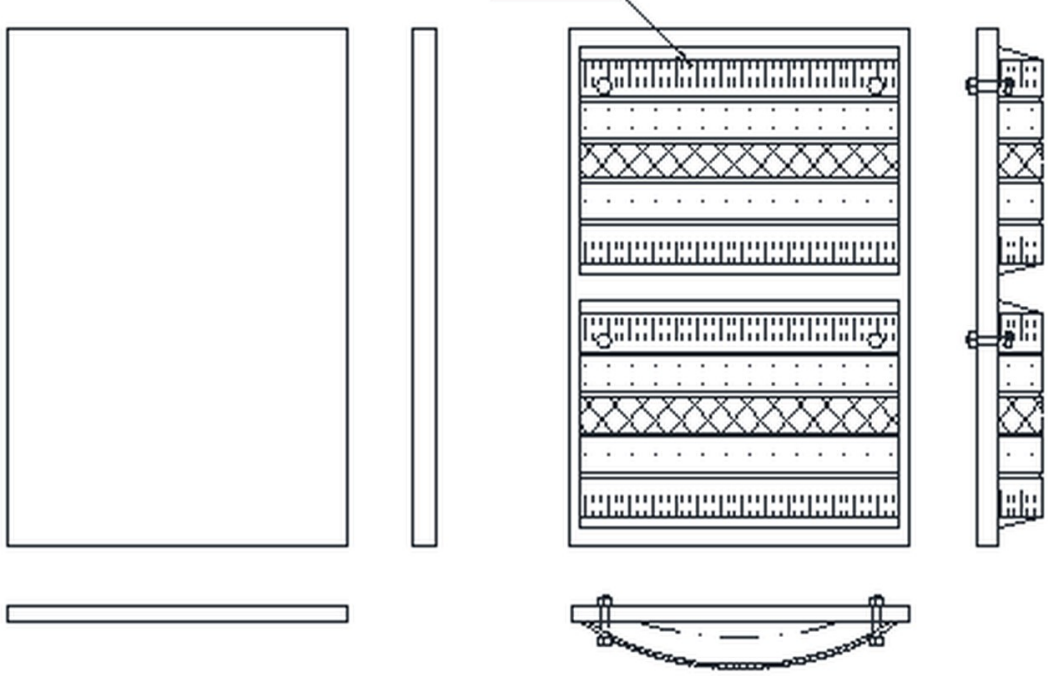

Fig. 8. Installing the IAZ to front shield
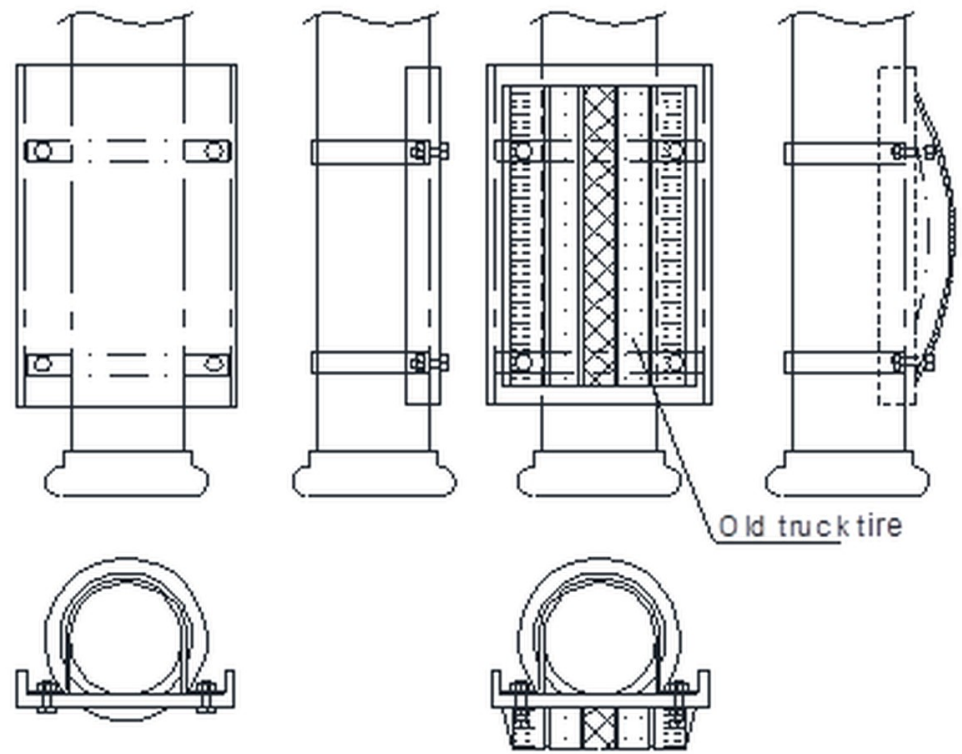

Fig. 9. Installing the IAZ to rear shield

\section{Conclusions}

This measures are cheap and environmental friendliness. The paper proved that the ability to reduce impulse which impact the support fatally as well as increase support's longevity but didn't calculate how many percent of impact force that IAZ could reduce. Finite Element Method can solve that problem however it's hard for seek parameters of materials. Real test is the method that gives the most accurate results. 


\section{References}

1. V.V. Kovalenko Mining informational and analytical bulletin Journal, 14, 267 (2004)

2. Nguyen Phi Hung, Journal of mining and earth sciences, 58, 80 (2017)

3. Hoang Van Vi. Hanoi.Vinacomin Institute of Mining \& Energy Mechanical Engineering (2010)

4. I. Pochinkov, A. Myaskov. Mining informational and analytical bulletin Journal, 5, 76 (2013)

5. Chen Chong, Yao Enguang, Zhang Zhe. Zhongzhou, Coal, 1, 4 (2013)

6. Bragin E.P., Vitcalov V.G, Pham Trung Nguyen, Mining informational and analytical bulletin Journal, 6, 37 (2010)

7. Wang Qingxiong, Ju Jinfeng, Coal Science and Technology, 42, 125 (2014)

8. Bie Xiaofei, Zhai Xinxian, Zhang Shuai, Coal Science and Technology, 41, 80 (2014)

9. E. Hoek, Mining Magazine, 282 (1998)

10. L. Martin, Public Health Service, Centers for DiseaseControl and Prevention, National Institute for Occupational Safety and Health, DHHS (NIOSH) Publication, 1 (2000) 